\title{
PRODUÇÃO DE PAVIMENTO INTERTRAVADO COM A UTILIZAÇÃO DE RESÍDUOS DA CONSTRUÇÃO CIVIL COMO AGREGADO MIÚDO
}

\author{
Regislaine Damasio Barreto ${ }^{1}$ \\ Marina Rico Toro Del Rio² \\ Erika Peterson Gonçalves ${ }^{3}$
}

\begin{abstract}
Resumo: Neste trabalho desenvolveu-se o estudo de pavimentos intertravados com agregado miúdo utilizando material reciclado, ou seja, o resíduo gerado por demolição de construções. Foram feitos testes nas peças, chegando a resultados que atendem as expectativas de serem aplicados em calçadas, sem fins estruturais. O pavimento intertravado é um pavimento por si só ecológico, tem maior durabilidade e reduz à temperatura em relação á outros tipos de pavimentos têm uma grande capacidade de drenagem, baixa e fácil manutenção e redução de custo. O sistema é intertravado, os pavers se encaixam uns nos outros como um quebra-cabeça, possibilitando a personalização e troca rápida de peças, a drenagem e devolução de água ao solo por conta de suas fissuras.

Palavras-chave: Pavers, Rsíduo de construção civil; Pavimento permeável.
\end{abstract}

\footnotetext{
${ }^{1}$ Faculdade de Engenharia, Arquitetura e Urbanismo - FEAU/Universidade do Vale do Paraíba - UNIVAP, Brasil. E-mail: regi.damasio@hotmail.com.

2 Faculdade de Engenharia, Arquitetura e Urbanismo - FEAU/Universidade do Vale do Paraíba - UNIVAP, Brasil. E-mail: marinadelrio19@hotmail.com.

${ }^{3}$ Faculdade de Engenharia, Arquitetura e Urbanismo - FEAU/Universidade do Vale do Paraíba - UNIVAP, Brasil. E-mail: erika@univap.br.
} 